\title{
Occupation-associated health hazards for the gastroenterologist/ endoscopist
}

\author{
Emmanuel Oforia, Daryl Ramaia,b, Febin John ${ }^{a}$, Madhavi Reddy ${ }^{a}$, Vishal Ghevariyac
}

The Brooklyn Hospital Center, Academic Affiliate of The Icahn School of Medicine at Mount Sinai, Clinical Affiliate of The Mount Sinai Hospital, New York; St George's University School of Medicine, True Blue, Grenada, W.I.; Eden Medical Center, Castro Valley, CA, USA

\begin{abstract}
Advances in the field of endoscopy have allowed gastroenterologists to obtain detailed imaging of anatomical structures and to treat gastrointestinal diseases with endoscopic therapies. However, these technological developments have exposed endoscopists and staff to hazards such as musculoskeletal injuries, exposure to infectious agents, and ionizing radiation. We aimed to review the occupational hazards for the gastroenterologist and endoscopist. Using PubMed, Medline, Medscape, and Google Scholar, we identified peer-reviewed articles with the keywords "occupational hazards," "health hazards," "occupational health hazards," "endoscopy," "gastroenterologist," "infectious agents," "musculoskeletal injuries," and "radiation." Strategies for reducing exposure to infectious agents, radiation, and the risk of musculoskeletal injuries related to gastroenterology include compliance with established standard measures, the use of thyroid shields and radioprotective eyewear, and ergonomic practices. We conclude that educating endoscopic personnel and trainees in these practices, in addition to further research in these areas, will likely lead to the development of more efficient and user-friendly workspaces that are safer for patients and personnel.
\end{abstract}

Keywords Occupational hazards, health hazards, occupational health hazards, endoscopy, gastroenterologist, infectious agents, musculoskeletal injuries, radiation

Ann Gastroenterol 2018; 31 (4): 1-8

\section{Introduction}

Endoscopists and staff are exposed to potential health hazards during diagnostic and therapeutic procedures. These include bodily and infectious fluids, exposed wires, radiation, and musculoskeletal injuries. Consistent adherence to safety protocols and practices must be followed to ensure that endoscopy personnel are protected against these hazards. The

${ }^{a}$ Division of Gastroenterology and Hepatology, The Brooklyn Hospital Center, Academic Affiliate of The Icahn School of Medicine at Mount Sinai, Clinical Affiliate of The Mount Sinai Hospital, New York (Emmanuel Ofori, Daryl Ramai, Febin John, Madhavi Reddy); bSt George's University School of Medicine, True Blue, Grenada, W.I. (Daryl Ramai); 'Eden Medical Center, Castro Valley, CA (Vishal Ghevariya), USA

Conflict of Interest: None

Correspondence to: Daryl Ramai, MD, MScBR, The Brooklyn Hospital Center, Academic Affiliate of The Icahn School of Medicine at Mount Sinai, Clinical Affiliate of The Mount Sinai Hospital, 121 Dekalb Avenue, Brooklyn, New York 11201, USA, e-mail: dramai@tbh.org

Received 6 March 2018; accepted 11 March 2018; published online 27 April 2018

DOI: https://doi.org/10.20524/aog.2018.0265
Occupational Safety Health Administration (OSHA) requires employers to assess the potential risk of each task and provide appropriate training and necessary protective equipment and apparel to reduce harmful exposure [1].

Furthermore, during gastrointestinal procedures, infectious agents may be transmitted from patients to endoscopy personnel or may spread to adjacent tissues breached during the procedures $[2,3]$. Meanwhile, radiation exposure from the use of fluoroscopy in procedures such as endoscopic retrograde cholangiopancreatography (ERCP) places both patients and personnel at risk for long-term injury. While the exposure to ionizing radiation during one endoscopic procedure is negligible, chronically the effect is cumulative. Moreover, gastroenterologists spend about $45 \%$ of their time performing endoscopic procedures and perform an average of 12 esophagogastroduodenoscopies and 22 colonoscopies per week [4]. This number tends to be higher in high-volume teaching institutions [4].

Concurrently, the need for ergonomic evaluation is paramount to avoiding injuries in endoscopy. Risk factors related to strain injury include repetition, prolonged awkward postures, high forces, contact stress, and vibration [5]. Surveybased studies report that the prevalence of musculoskeletal symptoms ranges from approximately $37-89 \%$, with pain in the thumb, hands, neck, and back being the most commonly 
reported [6-11]. We aimed to review the occupation-associated health hazards for the gastroenterologist and the evidencebased approaches that can be employed to minimize harm or exposure.

\section{Materials and methods}

We conducted an extensive English literature search using PubMed, Medline, Medscape, and Google Scholar to identify peer-reviewed original research and review articles using the keywords "occupational hazards," "health hazards," "occupational health hazards," "endoscopy," "gastroenterologist," "infectious agents," "musculoskeletal injuries," and "radiation." The search period included articles published from January 1, 1992 to January 18, 2018. We selected studies involving human models and manually searched the references to identify additional relevant studies.

\section{Infectious exposure}

Infectious disease exposure during endoscopy is a potential risk for both patients and endoscopic personnel. There is ample evidence of transmission of infections to patients undergoing gastrointestinal endoscopic procedures [2,3]. Patients acquire these infections via contaminated equipment, breach of mucosal integrity during the procedure spreading infection into the bloodstream or to adjacent organs, or direct transmission from endoscopy staff [3]. Bacterial transmission during gastrointestinal endoscopy was first reported in the late $20^{\text {th }}$ century and the common organisms identified were Salmonella, Pseudomonas, Klebsiella, Enterobacter, Serratia, and Staphylococcus $[3,12]$. These infections were found to be due to lack of proper reprocessing of endoscopes; however, with the adoption of current reprocessing guidelines, the bacterial transmission has become negligible. Transmissions of hepatitis B virus (HBV), hepatitis $\mathrm{C}$ virus (HCV), human immunodeficiency virus (HIV), fungi or parasites have not been reported since the adoption of standard reprocessing guidelines [3,13-17].

While reports exist on HIV, HBV, and HCV transmission to healthcare professionals in other healthcare settings, endoscopy is considered low risk for infectious transmission, as there is minimal direct contact with patients' body fluids. However, if precautions are not taken, there is potential for transmission by needle-stick injury, a splash of bodily fluids or inhalation of aerosolized infectious agents. An extensive review of the literature yielded less than 10 reports on the subject, which may reflect either the rarity of infectious transmission during endoscopy or its underreporting $[2,3,12,15,16,18-20]$.

Several reports indicate a high risk of Helicobacter pylori (H. pylori) transmission among endoscopy staff. In a study involving 122 gastro-endoscopists and endoscopic nurses, $H$. pylori infection was more common in endoscopic personnel than the general population [19]. No statistical difference was observed with respect to sex, years involved in endoscopy or the number of endoscopies performed monthly, and the investigators concluded that H. pylori should be viewed as an occupational hazard. Peter et al reported that the incidence of $H$. pylori infection is about $2.6 \%$ per year among endoscopists [20]. The same study also reported that compared to non-medical controls, endoscopists had twice as much risk (odds ratio [OR] 1.6, 95\% confidence interval [CI] 1.3-2.0) of acquiring $H$. pylori infection [19]. It is likely that the spread of $H$. pylori occurs via oral contamination by microscopic droplets of gastric juice from infected patients [20].

In a survey of endoscopy personnel, the risk of HIV transmission was perceived to be low [16]. In contrast, a study comparing controls (diarrhea and negative Clostridium difficile toxin (CDT) A and B) and cases (positive for CDT A and/or B) showed that the case-group had higher endoscopy exposure and were twice as likely to have Clostridium difficile (C. difficile) infection within 30 days (OR 2.09, 95\%CI 0.98-4.75) [12]. However, the study bordered on statistical significance $(\mathrm{P}=0.58)$. The prevention of $H$. pylori, HIV, or $C$. difficile requires the adoption of the well-established infection control guidelines [21]. For instance, the routine use of a facemask during endoscopy has been suggested to prevent transmission of $H$. pylori [20]. Adherence to standard precautions assessed in a survey by Angtuaco et al found that only $46 \%$ of gastroenterologists and $60 \%$ of endoscopy nurses were compliant with standard precaution measures [14]. Survey participants reported that busy practices, interference with skills or decreased efficiency were the common reasons for non-compliance. Kuwabara et al reported a lack of adequate training and unavailability of personal protective equipment as reasons for reduced compliance among endoscopy personnel [22].

\section{Decreasing infectious transmission}

Adherence to current endoscope reprocessing guidelines is crucial in preventing transmission of infections [23]. Disinfection with $2 \%$ glutaraldehyde for 5 and 10 minutes is effective in eliminating $H$. pylori DNA from endoscopes [24,25]. Additionally, 2\% glutaraldehyde and peracetic acid can destroy large numbers of $C$. difficile endospores during exposure times of 5-20 min [26-28]. Hand washing before and after each patient encounter, irrespective of the use of gloves, is strongly advised. Proper disposal of sharps and embracing needleless drug delivery systems can also help reduce infectious spread within endoscopy units (Table 1). Adoption of standard precautions during patient care, routine use of a facemask, the inclusion of standard precautions in the training curriculum for endoscopic personnel and ensuring the availability of personal protective gear are also paramount for minimizing infectious spread $[3,21]$. However, in the event of inadvertent exposure, personnel should follow hospital protocol or those outlined by OSHA and the U.S. Public Health Service. 
Table 1 Measures for reducing the transmission of infectious agents

\begin{tabular}{l}
\hline Adherence to endoscope reprocessing guidelines \\
Hand washing before and after each procedure \\
Use of gloves \\
Proper disposal of needles or sharps \\
Adoption of needleless drug delivery systems \\
Use of facemasks \\
Use of disposal aprons \\
\hline
\end{tabular}

\section{Musculoskeletal injuries}

Repetitive work, in addition to prolonged awkward postures associated with endoscopy place gastroenterologists at risk for overuse injuries, such as carpal tunnel syndrome, De Quervain's tenosynovitis, and lateral epicondylitis [29]. Ergonomics, however, continues to be a neglected aspect of gastro-endoscopic training and practice [30]. Only a handful of articles have been published on the subject. Furthermore, the percentage of musculoskeletal complaints surveyed by the American Society for Gastrointestinal Endoscopy increased from $57 \%$ in 1994 to $78 \%$ in 2006 and is expected to increase still further [6,31]. A survey of 684 endoscopists reported that $362(53 \%)$ experienced a musculoskeletal injury perceived to be definitely $(n=204)$ or possibly $(n=158)$ related to endoscopy [32]. Reported factors associated with a higher rate of endoscopy-related injury included a higher procedure volume ( $>20$ cases/week; $\mathrm{P}<0.001)$, a greater number of hours per week spent performing endoscopy $(>16 \mathrm{~h} /$ week; $\mathrm{P}<0.001)$, and the total number of years performing endoscopy $(\mathrm{P}=0.004)$. Additionally, the most common sites of injury were the neck and/or upper back (29\%) and thumb (28\%).

Liberman et al reported injuries to the hands, fingers, neck, and back as common occurrences while performing colonoscopy [30]. Cappell described the condition of "colonoscopist's thumb," a result of repetitive abduction and extension of the left thumb in the manipulation of the colonoscope dials [33]. Another such injury of overuse is the "biliary endoscopist's knuckle" which results from the repeated advancing of biliary instruments through often narrow strictures and the tight grip used when handling the pusher catheters [34].

Other studies have highlighted accidents that resulted in musculoskeletal injuries, including crushed hand against the doorway during patient transport, head strike on mounted monitors, slip and fall on wet floors, back and wrist sprain while breaking a fall, and trip and fall over exposed wires, cords and oxygen tubing [35,36]. Moreover, it is estimated that, on average, endoscopic-related musculoskeletal injuries result in 6 lost working days and 9 restricted work days $[35,36]$. Thus, the need for ensuring proper ergonomic practice impacts endoscopic personnel, patients, and hospital systems.

\section{Treatment}

Treatments for the various musculoskeletal injuries sustained ranged from as simple as acetaminophen and ibuprofen therapy for a few days to as severe as open surgical reduction and fixation of fractures. Of 17 endoscopists and staff who sustained endoscopy-associated musculoskeletal injuries, 7 were treated with only acetaminophen or ibuprofen for about 5-10 days; 4 individuals had a combination therapy with acetaminophen or ibuprofen and a plaster cast or digit/ wrist splinting; 1 person was treated with a knee immobilizer and 7 days of ibuprofen for her left knee contusion due to a slip and fall on a wet floor; another individual had an open surgical reduction and fixation for right-hand metacarpal and digit fractures sustained after a trip and fall over exposed wires on the floor; and another individual required hydrocodone, corticosteroid injections to a herniated disc and intensive physical therapy for back injury while positioning a patient during endoscopy $[35,36]$. Ridtitid et al reported that only $55 \%$ of injured endoscopists applied practice modifications in response to injuries [23]. Specific treatments included medications (57\%), steroid injection (27\%), physiotherapy (45\%), rest (34\%), splinting (23\%), and surgery (13\%).

\section{Decreasing musculoskeletal injuries}

To minimize musculoskeletal injuries in endoscopy, routine ergonomic principles should be incorporated. Endoscopy suites should be designed ergonomically to accommodate the variety of body structures of endoscopy personnel. Net neutral body positions allow for maximum force to be applied with minimal energy exertion [37]. Such net neutral body positions prevent strain and injury to body parts. During endoscopic procedures, the monitors should be located directly in front of the endoscopist at a height adjustable to the endoscopist's preference, in order to reduce strain on the back and neck [37] (Fig. 1). The procedure table height should also be adjustable to allow for neutral elbow, shoulder and back postures [17]. Shergill et al noted that the endoscope insertion tube should be held in the right hand and $10 \mathrm{~cm}$ below elbow height for effective handling [38].

Optimal interaction of the endoscopist and endoscope during procedures decreases the potential for overuse injuries. In a colonoscopy, the repetition and potential for high forces during torques and advancement of the colonoscope tip can lead to an overuse injury in the left thumb on the control dials and to the right hand as it advances the colonoscope [17]. Rex et al described the technique of the "left-hand shaft grip" to assist the left thumb in maneuvering sharp turns or difficult polypectomies [38]. The "left-hand shaft grip" thereby frees the right hand to help with controlling the dials and limiting excessive torqueing (Fig. 2). Additionally, $\mathrm{Hu}$ et al proposed the scissors finger, elbow, and thighs maneuvers for reduction of left-hand strain while doing a colonoscopy in a sitting position [39]. Sitting during colonoscopy reduces strain on the lower back; however, only a few endoscopists do it [8] (Fig. 3). 


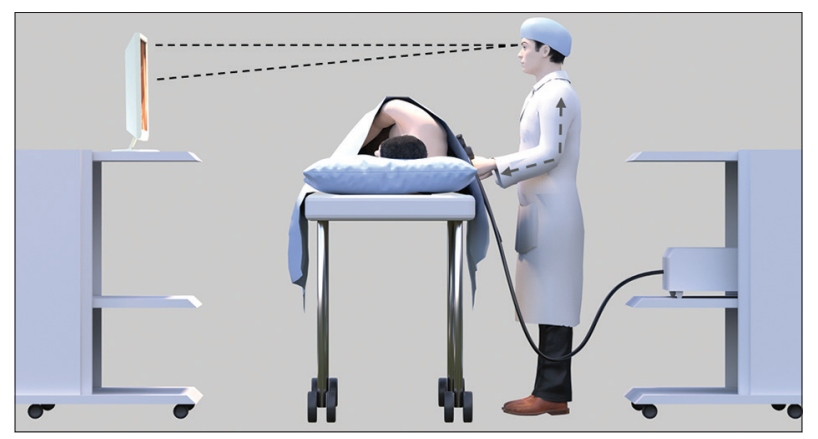

Figure 1 Schematic representation of a monitor located directly in front of the endoscopist, with the height of the patient table adjusted to reduce strain on the arms, back and neck
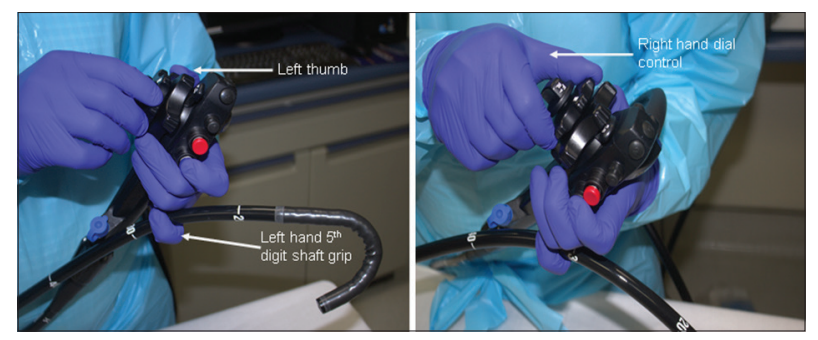

Figure 2 Left-hand shaft grip frees the right hand to assist the left thumb with dial control in maneuvering sharp turns or difficult polypectomies while limiting excessive torqueing
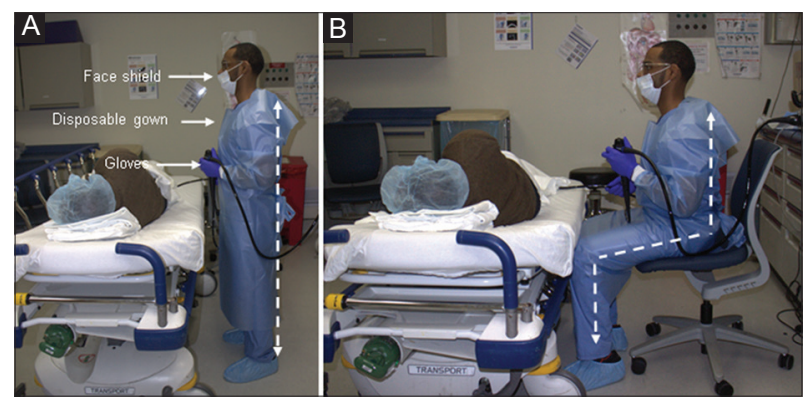

Figure 3 Gastroenterologist wearing protective personal equipment while standing (A) or sitting (B) during endoscopic procedures

In addition, ensuring breaks during multiple procedures to allow for recovery of muscle fatigue is also an important way of preventing overuse injuries [37]. Cushioned mats and insoles have been suggested to improve endoscopist's comfort during long hours of standing while performing procedures [31]. Accidental falls over exposed wires may be prevented by bundling wires, running wires from ceiling outlets or covering them on the floor with non-slip mats [35]. Additionally, the use of wireless medical devices can decrease the risk of tripping over wires in the endoscopy unit [40].

The above techniques reduce the incidence of musculoskeletal injuries to a certain extent but do not eliminate it. Thus, ergonomic endoscope design might minimize the force required to generate adequate torque. Self-propelling scopes, such as the Aer-O-Scope and the Slightline ColonoSight, and the "motor-driven" Invendo colonoscope eliminate the forces on hands and joints associated with scope insertion, torqueing and advancement [41-43]. Conventional methods, such as reducing the colonoscope to ensure one-to-one transfer in scope advancement, can help to prevent loop formation.

\section{ERCP radiation}

Energy transmission from a source via waves or particles is generally referred to as radiation. Ionizing radiation is energy capable of interacting with electrons, which results in charged or ionized particles including alpha-, beta-, gamma- and $\mathrm{x}$-rays. The human cellular injury caused by ionizing radiation has two main outcomes: 1) direct cellular damage; and 2) production of reactive oxygen species, which leads to indirect cell damage [44]. Radiation injury is dependent on the stage of differentiation, type of cell, age, and internal/external microenvironments [45]. Consequently, different tissues display varying sensitivities, as injury may result in two forms: 1) deterministic, and 2) stochastic. The most commonly encountered stochastic injuries are to the skin and lens while the most concerning deterministic injury is malignant transformation [44].

Radiation exposure from ERCP is mainly derived from the use of fluoroscopy, in which both patients and ERCP personnel are at risk $[46,47]$. Chronically, the cumulative effects of radiation can result in malignancies and benign conditions such as cataracts if adequate protection is not used [48]. To this end, the International Commission on Radiological Protection recommends that total body exposure not exceed $50 \mathrm{mSv}$ per year [49]. The recommended limit for optic radiation by the United States Nuclear Regulatory Commission is $150 \mathrm{mSv}$.

\section{Whole-body radiation exposure}

Naidu et al examined 61 ERCP procedures and estimated that the annual whole-body effective dose equivalent received by endoscopists ranged between 3.35 and $5.87 \mathrm{mSv}$, doses higher than those considered acceptable for the public [50]. Additionally, the estimated radiation exposure to the thyroid gland for endoscopists was between 25.8-85.2 mSv. Sulieman et $a l$, in a study involving 57 ERCP cases, reported average exposure rates of $6.2 \mathrm{uSv}, 3.81 \mathrm{uSv}, 27 \mathrm{uSv}$ and $5.4 \mathrm{uSv}$ for chest, forehead, hands and thyroid, respectively [51]. Buls et al reported 54 ERCP cases with a median dose of $0.30 \mathrm{mSy}$ per procedure to the skin at the level of the thyroid and $0.44 \mathrm{mSv}$ to the skin of the hands [52].

\section{Ocular radiation exposure}

The same study by Buls et al reported a median ocular dose of $0.34 \mathrm{mSv}$ per procedure [52]. A similar study by Garg et al measured optic radiation exposure in attendings and fellows after 187 ERCP cases [53]. The cumulative radiation dose 
absorbed per lens dosimeter was $5.35 \mathrm{mSv}$ for attendings and $2.55 \mathrm{mSv}$ for fellows. The findings project that procedure times of $59.41 \mathrm{~h}$ for attendings and $88.17 \mathrm{~h}$ for fellows are needed to reach the lens threshold limit (20 mSv/year) [53]. Zagorska et al evaluated 15 ERCP cases and reported ocular exposure between 19.4 and $25.6 \mathrm{mSv}$, values above or around the annual dose limit [54]. O'Connor et al reported after a six-week study that the mean dose of radiation to the left eye was 0.01 $\mathrm{mSv}$, which had a projected annual dose of $1.3 \mathrm{mSv}$ (based on a workload of 130 ERCP cases) [55]. Furthermore, it was noted that patient radiation exposure was significantly higher when ERCPs were performed by a low-volume provider [56]. The difference in exposure time was further augmented after adjusting for procedural complexity. Similarly, Oztas et al reported 110 consecutive therapeutic ERCP procedures that measured an average of $72 \mu \mathrm{Sv}$ [57]. The study deduced that an endoscopist would have to perform 1850 procedures annually to exceed the recommended limit.

\section{Decreasing exposure}

The effects of radiation exposure are further exacerbated when gastroenterologists or staff do not wear full protective clothing: protective aprons, thyroid shield, and lead glasses (Fig. 4). The studies reported above serve as a reminder of the importance of proper equipment, as well as following "as low as reasonably achievable" (ALARA) recommendations to reduce radiation exposure [58]. The fundamental principle of ALARA implies that if receiving a dose of radiation (even if small) has no direct benefit, then it should be avoided. However, if radiation must be used, ALARA measures should be followed (Table 2) [59].

While whole-body radiation can be easily reduced, the issue of optic radiation exposure remains concerning. The crystalline lens of the eye is regarded as being one of the most radiosensitive tissues in the body and the cumulative effect of optic radiation is a risk factor for the onset of cataracts [60]. To this end, academic societies such as the Cardiovascular and Interventional Radiology Society of Europe strongly advise interventionalists and staff to wear radioprotective glasses at all times [61]. However, the guidelines or current recommendations from American gastroenterology societies only suggest using radioprotection for high case-loads or with over-couch systems. The European Society of Disease Endoscopy's 2012 guideline on radiation protection recommends reducing radiation exposure by positioning the patient as far as possible from the X-ray tube, limiting fluoroscopy time, using pulsed fluoroscopy instead of continuous fluoroscopy, selecting the lowest reasonable image quality, avoiding unnecessary magnification, limiting the number of radiographic still images, and having more experienced endoscopists deal with complex cases [62].

Other factors that can affect radiation dose include the type of X-ray tube used (over-couch C-arm units vs. undercouch units), mobile vs. stationary $\mathrm{X}$-rays and the total time spent in fluoroscopy during the procedure (a collinear

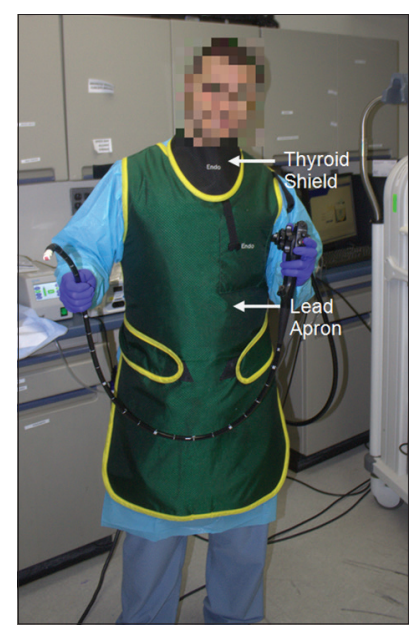

Figure 4 Use of protective equipment to reduce radiation exposure using thyroid shield, lead body apron, and radioprotective eyeglasses (not shown here)

Table 2 "As low as reasonably achievable" (ALARA) recommendations for reducing radiation exposure

\begin{tabular}{l}
\hline Minimize time near a radioactive source \\
Maximize the distance between personnel and radioactive sources \\
Use a shield to protect against radiation \\
Use the lowest needed magnification \\
Keep angulation to a minimum \\
Use fluorosave instead of acquisition images \\
Add 0.1 mm Cu filtration for all protocols \\
Keep the detector close to the patient \\
Use beam collimation whenever possible \\
\hline
\end{tabular}

relationship) [63,64]. Additionally, radiation exposure varies according to physician education and experience, altered anatomy and various procedure-specific factors, including stent insertion, lithotripsy, taking biopsies, and the use of instruments [65-70]. An observational study from Greece reported that fluoroscopy time was prolonged by choledocholithiasis, multiple common bile duct stones, stone size greater than $10 \mathrm{~mm}$, needle-knife papillotomy, the presence of periampullary diverticulum and mechanical lithotripsy [71]. Recently, Johawi et al, in a retrospective analysis of 299 ERCPs, reported that decreasing the distance between the endoscopist and the fluoroscopy screens in the ERCP suite significantly reduced the total fluoroscopy time and therefore the radiation exposure to staff involved in the procedure [72].

Radiation can be restricted to the smallest possible area by using beam-limiting devices, including aperture diaphragms, cones and cylinders, collimators and grids [73]. Of these, collimation is the most commonly used; it functions by reducing the amount of scattering and aligning radiation waves in a single direction. Thosani et al reported a linear 
relationship between collimation and radiation dose received during ERCP [74]. The study found that collimation reduced radiation exposure by $50 \%$. Given the rarity of data and lack of information in this area, additional studies are needed to investigate the practical application of-beam limiting devices in ERCP.

The need to reduce the amount of radiation has led to the development of radiation-free techniques such as direct solitary cholangioscopy, endoscopic biliary sphincterotomy plus papillary balloon dilation, and endoscopic ultrasound-based ERCP [75-79]. Initial studies have demonstrated their clinical feasibility and particular relevance to pregnant women, in whom any radiation exposure should be avoided [80-81]. While these radiation-free techniques are promising, they require additional training and commitment towards the evolution of ERCP into a non-radiographic-based procedure [82].

\section{Concluding remarks and future directions}

The Centers for Disease Control and Prevention (CDC) recommend the use of personal protective equipment for anticipated exposure. However, as stated earlier, there are no endoscopy-related guidelines for the use of such equipment. Endoscopic personnel must be aware of the risks associated with gastrointestinal procedures and the interventions used. To this end, appropriate precautions should be tailored to the procedure being performed.

The CDC recommends using standard precautions, such as wearing gloves, gowns, and face shields or masks, to minimize the risk of infection. While these are very basic measures, if used appropriately they can protect endoscopic personnel from splashes, sprays of blood, body fluids, secretions or excretions [13]. Surveys among endoscopists report less than $50 \%$ compliance with universal precautionary measures [14]. The risk of mucocutaneous exposure to body fluids is greater during an endoscopy. Mohandas and Gopalakrishnan reported that mucocutaneous exposure occurred in approximately $13 \%$ of procedures or more [15]. In addition, the study reported a splash rate of $9.5 \%$ to the face, forearms, and feet, and $4.1 \%$ to the eyes [15].

Lead aprons are indicated for all endoscopy personnel in order to counteract and protect against radiation. Chen et al reported that the use of a protective lead shielding reduced radiation exposure from an average of $1.5 \mathrm{mR}$ per diagnostic ERCP and $3.17 \mathrm{mR}$ per therapeutic ERCP (without shielding) to an average of $0.25 \mathrm{mR}$ per diagnostic procedure and 0.28 $\mathrm{mR}$ per therapeutic procedure [46]. While it is not a universal requirement, thyroid shields or guards have been shown to reduce the total body effective dose by $46 \%$ per year [83]. To avoid ocular damage, recent studies by Garg et al recommend the use of radioprotective eyewear by physicians and fellows exposed to radiation for more than $59.4 \mathrm{~h}$ and $88.2 \mathrm{~h}$, respectively [53]. More robust precautions should be taken in centers that utilize more advanced imaging or endoscopic procedures.

Ergonomic measures aimed at reducing strain and other related injuries should be tailored to meet the needs of endoscopists. No study has evaluated interventions to reduce the risk factors associated with endoscopic musculoskeletal injuries. However, lessons and principles can be applied from other workplace interventions. A pilot study reported that a 1-piece lead apron was associated with significantly more neck and lower back discomfort compared with a 2-piece lead apron [84]. Softer flooring has been subjectively associated with less fatigue and reduced lower extremity and back discomfort [85]. A similar finding was reported for the use of insoles [86]. Compression stockings can also offer a potential benefit to personnel with chronic venous insufficiency, or during prolonged standing [87]. However, none of these interventions have been objectively tested in an endoscopic suite. The practicality of certain interventions also warrants further study and discussion.

\section{Acknowledgment}

The authors would like to thank Mr. Sahrin Samad for the medical illustrations.

\section{References}

1. Occupational Safety and Health Administration. Quick Reference Guide to the Bloodborne Pathogens Standard. https://www.osha. gov/SLTC/bloodbornepathogens/bloodborne_quickref.html [Accessed Apr 02, 2018].

2. Kimmery MB, Burnett DA, Carr-Locke DL, et al. Transmission of infection by gastrointestinal endoscopy. Gastrointest Endosc 1993;39:885-888.

3. Banerjee S, Shen B, Nelson DB, et al; ASGE Standards of Practice Committee. Infection control during GI endoscopy. Gastrointest Endosc 2008;67:781-790.

4. Cohen LB, Wecsler JS, Gaetano JN, et al. Endoscopic sedation in the United States: results from a nationwide survey. Am J Gastroenterol 2006;101:967-974.

5. Rempel DM, Harrison RJ, Barnhart S. Work-related cumulative trauma disorders of the upper extremity. JAMA 1992;267:838-842.

6. Buschbacher R. Overuse syndromes among endoscopists. Endoscopy 1994;26:539-544.

7. Byun YH, Lee JH, Park MK, et al. Procedure-related musculoskeletal symptoms in gastrointestinal endoscopists in Korea. World $J$ Gastroenterol 2008;14:4359-4364.

8. Hansel SL, Crowell MD, Pardi DS, Bouras EP, DiBaise JK. Prevalence and impact of musculoskeletal injury among endoscopists: a controlled pilot study. J Clin Gastroenterol 2009;43:399-404.

9. Keate RF, Dryden GW, Wang K, Chen YK. Occupational injuries to endoscopists: report from the ASGE Web survey. Gastrointest Endosc 2006;63:AB111.

10. O’Sullivan S, Bridge G, Ponich T. Musculoskeletal injuries among ERCP endoscopists in Canada. Can J Gastroenterol 2002;16:369-374.

11. Yung DE, Banfi T, Ciuti G, Arezzo A, Dario P, Koulaouzidis A. Musculoskeletal injuries in gastrointestinal endoscopists: a systematic review. Expert Rev Gastroenterol Hepatol 2017;11:939-947.

12. Selinger CP, Greer S, Sutton CJ. Is gastrointestinal endoscopy a risk factor for Clostridium difficile associated diarrhea? Am J Infect 
Control 2010;38:581-582.

13. Siegel JD, Rhinehart E, Jackson M, Chiarello L. 2007 guideline for isolation precautions: preventing transmission of infectious agents in health care settings. Am J Infect Control 2007;35:S65-S164.

14. Angtuaco TL, Oprescu FG, Lal SK, et al. Universal precautions guideline: self-reported compliance by gastroenterologists and gastrointestinal endoscopy nurses-a decade's lack of progress. Am J Gastroenterol 2003;98:2420-2423.

15. Mohandas KM, Gopalakrishnan G. Mucocutaneous exposure to body fluids during digestive endoscopy: the need for universal precautions. Indian J Gastroenterol 1999;18:109-111.

16. Shapiro M, Brandt LJ. Endoscopy in the age of HIV: a study of current practices and attitudes. Gastrointest Endosc 1994;40:477-480.

17. Petersen BT, Chennat J, Cohen J, et al. Multisociety guideline on reprocessing flexible gastrointestinal endoscopes: 2011. Gastrointest Endosc 2011;73:1075-1084.

18. Chong J, Marshall BJ, Barkin JS, et al. Occupational exposure to Helicobacter pylori for the endoscopy professional: a sera epidemiological study. Am J Gastroenterol 1994;89:1987-1992.

19. Peters C, Schablon A, Harling M, Wohlert C, Costa JT, Nienhaus A. The occupational risk of Helicobacter pylori infection among gastroenterologists and their assistants. BMC Infect Dis 2011;11:154.

20. Hildebrand P, Meyer-Wyss BM, Mossi S, Beglinger C. Risk among gastroenterologists of acquiring Helicobacter pylori infection: casecontrol study. BMJ 2000;321:149.

21. Pedrosa MC, Farraye FA, Shergill AK, et al; ASGE Technology Committee. Minimizing occupational hazards in endoscopy: personal protective equipment, radiation safety, and ergonomics. Gastrointest Endosc 2010;72:227-235.

22. Kuwabara T, Chayama K, Tanaka S, Oka S, Hiyama T, Yoshihara M. Compliance with standard precautions among gastrointestinal endoscopists and endoscopy nurses in Japan. Am J Infect Control 2012;40:80.

23. Ridtitid W, Coté GA, Leung W, et al. Prevalence and risk factors for musculoskeletal injuries related to endoscopy. Gastrointest Endosc 2015;81:294-302.

24. Roosendaal R, Kuipers EJ, van Brule, et al. Importance of the fiberoptic endoscope cleaning procedure for detection of Helicobacter pylori in gastric biopsy specimens by PCR. J Clin Microbiol 1994;32:1123-1126.

25. Hughes CE, Gebhard RL, Peterson LR, Gerding DN. Efficacy of routine fiberoptic endoscope cleaning and disinfection for killing Clostridium difficile. Gastrointest Endosc 1986;32:7-9.

26. Rutala WA, Gergen MF, Weber DJ. Inactivation of Clostridium difficile spores by disinfectants. Infect Control Hosp Epidemiol 1993; 14:36-39.

27. Wullt M, Odenholt I, Walder M. Activity of three disinfectants and acidified nitrite against Clostridium difficile spores. Infect Control Hosp Epidemiol 2003;24:765-768.

28. Kovaleva J, Peters FT, van der Mei HC, Degener JE. Transmission of infection by flexible gastrointestinal endoscopy and bronchoscopy. Clin Microbiol Rev 2013;26:231-254.

29. Sheth A, Jordan P. Call for guidelines on ergonomics in GI endoscopy. Gastrointest Endosc 2010;71:1333; author reply 1333.

30. Liberman AS, Shrier I, Gordon PH. Injuries sustained by colorectal surgeons performing colonoscopy. Surg Endosc 2005;19:1606-1609.

31. Shelly A. Best practices: ergonomic standing surfaces for workers. Occup Health Saf 2005;74:128, 130-134.

32. Shergill AK, McQuaid KR, Rempel D. Ergonomics and GI endoscopy. Gastrointest Endosc 2009;70:145-153.

33. Cappell MS. Colonoscopist's thumb: DeQuervains's syndrome (tenosynovitis of the left thumb) associated with overuse during endoscopy. Gastrointest Endosc 2006;64:841-843.

34. Siegel JH, Kasmin EE, Cohen SA. Health hazards and endoscopy: the known and newly experienced-a personal report. Endoscopy 1994;26:545-548.

35. Cappell MS. Injury to endoscopic personnel from tripping over exposed cords, wires, and tubing in the endoscopy suite: a preventable cause of potentially severe workplace injury. Dig Dis Sci 2010;55:947-951.

36. Cappell MS. Accidental occupational injuries to endoscopy personnel in a high-volume endoscopy suite during the last decade: mechanisms, workplace hazards, and proposed remediation. Dig Dis Sci 2011;56:479-487.

37. Chengular SR, Rodgers SH, Bernard TE. Kodak's ergonomic design for people at work. $2^{\text {nd }}$ ed. John Wiley \& Sons, Inc: Hoboken, NJ; 2004.

38. Rex DK. Maximizing control of tip deflection with sound ergonomics: the "left hand shaft grip". Gastrointest Endosc 2007;65:950-951.

39. Hu CT. The SET maneuvers for reducing left-hand strain while doing colonoscopy in a sitting position. Gastrointest Endosc 2011;73:639-640.

40. Harvin G. Review of musculoskeletal injuries and prevention in the endoscopy practitioner. J Clin Gastroenterol 2014;48:590-594.

41. Rösch T, Adler A, Pohl H, et al. A motor-driven single-use colonoscope controlled with a hand-held device: a feasibility study in volunteers. Gastrointest Endosc 2008;67:1139-1146.

42. Vucelic B, Rex D, Pulanic R, et al. The aer-o-scope: proof of concept of a pneumatic, skill-independent, self-propelling, self-navigating colonoscope. Gastroenterology 2006;130:672-677.

43. Shike M, Fireman Z, Eliakim R, et al. Sightline ColonoSight system for a disposable, power-assisted, non-fiber-optic colonoscopy (with video). Gastrointest Endosc 2008;68:701-710.

44. Brown KR, Rzucidlo E. Acute and chronic radiation injury. J Vasc Surg 2011;53(1 Suppl):15S-21S.

45. Cairns RA, Harris IS, Mak TW. Regulation of cancer cell metabolism. Nat Rev Cancer 2011;1 1:85-95.

46. Chen MY, Van Swearingen FL, Mitchell R, Ott DJ. Radiation exposure during ERCP: effect of a protective shield. Gastrointest Endosc 1996;43:1-5.

47. Larkin CJ, Workman A, Wright RE, Tham TC. Radiation doses to patients during ERCP. Gastrointest Endosc 2001;53:161-164.

48. Ainsbury EA, Bouffler SD, Dörr W, et al. Radiation cataractogenesis: a review of recent studies. Radiat Res 2009;172:1-9.

49. International Commission on Radiological Protection Statement on Tissue Reactions. Report no. ICRP 4825-3093-1464. ICRP: Ottawa, ON, 2011.

50. Naidu LS, Singhal S, Preece DE, Vohrah A, Loft DE. Radiation exposure to personnel performing endoscopic retrograde cholangiopancreatography. Postgrad Med J 2005;81:660-662.

51. Sulieman A, Paroutoglou G, Kapsoritakis A, et al. Reduction of radiation doses to patients and staff during endoscopic retrograde cholangiopancreatography. Saudi J Gastroenterol 2011;17:23-29.

52. Buls N, Pages J, Mana F, Osteaux M. Patient and staff exposure during endoscopic retrograde cholangiopancreatography. $\mathrm{Br} \mathrm{J}$ Radiol 2002;75:435-443.

53. Garg MS, Patel P, Blackwood M, et al. Ocular radiation threshold projection based off of fluoroscopy time during ERCP. Am J Gastroenterol 2017;112:716-721.

54. Zagorska A, Romanova K, Hristova-Popova J, Vassileva J, Katzarov K. Eye lens exposure to medical staff during endoscopic retrograde cholangiopancreatography. Phys Med 2015;31:781-784.

55. O'Connor U, Gallagher A, Malone L, O'Reilly G. Occupational radiation dose to eyes from endoscopic retrograde cholangiopancreatography procedures in light of the revised eye lens dose limit from the International Commission on Radiological Protection. Br J Radiol 2013;86:20120289.

56. Coté GA. The provision of ERCP services in the United States is a 
radiating concern. Gastrointest Endosc 2015;81:399-401.

57. Oztas E, Parlak E, Kucukay F, et al. The impact of endoscopic retrograde cholangiopancreatography education on radiation exposure to experienced endoscopist: 'trainee effect'. Dig Dis Sci 2012;57:1134-1143.

58. Adler DG, Lieb JG $2^{\text {nd }}$, Cohen J, et al. Quality indicators for ERCP. Gastrointest Endosc 2015;81:54-66.

59. Kachaamy T, Harrison E, Pannala R, Pavlicek W, Crowell MD, Faigel DO. Measures of patient radiation exposure during endoscopic retrograde cholangiography: beyond fluoroscopy time. World J Gastroenterol 2015;21:1900-1906.

60. Hamada N, Fujimichi Y. Role of carcinogenesis related mechanisms in cataractogenesis and its implications for ionizing radiation cataractogenesis. Cancer Lett 2015;368:262-274.

61. MillerDL, VañóE, BartalG, etal; Society ofInterventional Radiology. Occupational radiation protection in interventional radiology: a joint guideline of the Cardiovascular and Interventional Radiology Society of Europe and the Society of Interventional Radiology. Cardiovasc Intervent Radiol 2010;33:230-239.

62. Dumonceau JM, Garcia-Fernandez FJ, Verdun FR, et al; European Society of Digestive Endoscopy. Radiation protection in digestive endoscopy: European Society of Digestive Endoscopy (ESGE) guideline. Endoscopy 2012;44:408-421.

63. Johlin FC, Pelsang RE, Greenleaf M. Phantom study to determine radiation exposure to medical personnel involved in ERCP fluoroscopy and its reduction through equipment and behavior modifications. Am J Gastroenterol 2002;97:893-897.

64. Cohen RV, Aldred MA, Paes WS, et al. How safe is ERCP to the endoscopist? Surg Endosc 1997;11:615-617.

65. Hernandez RJ, Goodsitt MM. Reduction of radiation dose in pediatric patients using pulsed fluoroscopy. AJR Am J Roentgenol 1996;167:1247-1253.

66. Scanavacca M, d' Avila A, Velarde JL, Reolão JB, Sosa E. Reduction of radiation exposure time during catheter ablation with the use of pulsed fluoroscopy. Int J Cardiol 1998;63:71-74.

67. Uradomo LT, Goldberg EM, Darwin PE. Time-limited fluoroscopy to reduce radiation exposure during ERCP: a prospective randomized trial. Gastrointest Endosc 2007;66:84-89.

68. Jorgensen J, Rubenstein J, Goodsitt $M$ et al. Radiation doses to ERCP patients are significantly lower with experienced endoscopists. Gastrointest Endosc 2011;72:58-65.

69. Uradomo LT, Lustberg ME, Darwin PE. Effect of physician training on fluoroscopy time during ERCP. Dig Dis Sci 2006;51:909-914.

70. Kim E, McLoughlin M, Lam EC, et al. Prospective analysis of fluoroscopy duration during ERCP: critical determinants. Gastrointest Endosc 2010;72:50-57.

71. Katsinelos P, Gatopoulou A, Gkagkalis S, et al. A prospective analysis of factors influencing fluoroscopy time during therapeutic ERCP. Ann Gastroenterol 2012;25:338-344.

72. Jowhari F, Hopman WM, Hookey L. A simple ergonomic measure reduces fluoroscopy time during ERCP: A multivariate analysis. Endosc Int Open 2017;5:E172-E178.

73. Meining A, Götz M. ERCP. In: Kähler G, Götz M, Senninger N (eds). Therapeutic Endoscopy in the Gastrointestinal Tract. Springer, Cham 2018, pp. 71-99.

74. Thosani NC, Wang J, Damavandi S, Chen AM, Friedland S, Banerjee S. Sul617 impact of fluoroscopy frame rate, image magnification, collimation and height of the image intensifier on radiation exposure to patients during ERCP. Gastrointest Endosc 2014;79:AB341.

75. Luangsukrerk T, Ridtitid W, Angsuwatcharakon P, Kongkam P, Kullavanijaya P, Rerknimitr R. Tu1428 outcomes of digital spyglass cholangioscopy (without fluoroscopy) versus conventional endoscopic retrograde cholangiopancreatography for common bile duct stone removal. Gastrointest Endosc 2017;85:AB622-AB623.

76. Shah JN, Bhat YM, Hamerski CM, Kane SD, Binmoeller KF. Feasibility of nonradiation EUS-based ERCP in patients with uncomplicated choledocholithiasis (with video). Gastrointest Endosc 2016;84:764-769.

77. Ersoz G, Turan I, Tekin F, Ozutemiz O, Tekesin O. Nonradiation ERCP with endoscopic biliary sphincterotomy plus papillary balloon dilation for the treatment of choledocholithiasis during pregnancy. Surg Endosc 2016;30:222-228.

78. Barakat MT, Girotra M, Choudhary A, Huang RJ, Sethi S, Banerjee S. A prospective evaluation of radiation-free direct solitary cholangioscopy for the management of choledocholithiasis. Gastrointest Endosc 2018;87:584-589.

79. Binmoeller KF. Nonradiation. Endoscopic ultrasound-based endoscopic retrograde cholangiopancreatography. Gastroenterol Hepatol (N Y) 2017;13:58-61.

80. Shelton J, Linder JD, Rivera-Alsina ME, Tarnasky PR. Commitment, confirmation, and clearance: new techniques for nonradiation ERCP during pregnancy (with videos). Gastrointest Endosc 2008;67:364-368.

81. Wu W, Faigel DO, Sun G, Yang Y. Non-radiation endoscopic retrograde cholangiopancreatography in the management of choledocholithiasis during pregnancy. Dig Endosc 2014;26:691-700.

82. Binmoeller KF, Nett A. ERCP: Time to take the lead off? Gastrointest Endosc 2017;86:1066-1069.

83. Niklason LT, Marx MV, Chan HP. Interventional radiologists: occupational radiation doses and risks. Radiology 1993;187:729-733.

84. Rothmore P. Lead aprons, radiographers and discomfort: a pilot study. J Occup Health Safety Aust NZ 2002;18:357-366.

85. Redfern MS, Cham R. The influence of flooring on standing comfort and fatigue. AIHAJ 2000;61:700-708.

86. King PM. A comparison of the effects of floor mats and shoe insoles on standing fatigue. Appl Ergon 2002;33:477-484.

87. Benigni JP, Sadoun S, Allaert FA, Vin F. Efficacy of Class 1 elastic compression stockings in the early stages of chronic venous disease. A comparative study. Int Angiol 2003;22:383-392. 